\title{
Expression of CXCL1 in human endothelial cells induces angiogenesis through the CXCR2 receptor and the ERK1/2 and EGF pathways
}

\author{
Makito Miyake ${ }^{1}$, Steve Goodison ${ }^{1,2}$, Virginia Urquidi ${ }^{1}$, Evan Gomes Giacoia ${ }^{1}$ and Charles J Rosser ${ }^{1,2}$
}

Endothelial cell growth and proliferation are critical for angiogenesis; thus, greater insight into the regulation of pathological angiogenesis is greatly needed. Previous studies have reported on chemokine (C-X-C motif) ligand 1 (CXCL1) expression in epithelial cells and that secretion of CXCL1 from these epithelial cells induces angiogenesis. However, limited reports have demonstrated CXCL1 expression in endothelial cells. In this report, we present data that expand on the role of CXCL1 in human endothelial cells inducing angiogenesis. Specifically, CXCL1 is expressed and secreted from human endothelial cells. Interference of CXCL1 function using neutralizing antibodies resulted in a reduction in endothelial cell migration and viability/proliferation, the latter associated with a decrease in levels of cyclin $D$ and cdk4. In vitro studies revealed that CXCL1 influenced neoangiogenesis through the regulation of epidermal growth factor and ERK1/2. In a xenograft angiogenesis model, interference of CXCL1 function resulted in inhibition of angiogenesis. A better understanding of the role of CXCL1 in the interactions between the endothelial and epithelial components will provide insight into how human tissues use CXCL1 to survive and thrive in a hostile environment. Laboratory Investigation (2013) 93, 768-778; doi:10.1038/labinvest.2013.71; published online 3 June 2013

KEYWORDS: angiogenesis; chemokine (C-X-C motif) ligand 1; endothelial cell; epidermal growth factor

The progressive growth of primary neoplasms and metastases is dependent on an adequate blood supply. The process of neovascularization, that is, angiogenesis, is required for tumors to expand beyond $1-2 \mathrm{~mm}^{3} .{ }^{1-3}$ The increase in vasculature also increases the probability that motile-invasive tumor cells may enter the circulation to disseminate to distant organs. ${ }^{4}$ The extent of vascularization differs between malignancies, and has been shown to correlate directly with metastatic potential. ${ }^{5}$

The induction of angiogenesis is mediated by positive and negative regulatory molecules released by tumor-associated epithelial cells, endothelial cells, mesothelial cells and leukocytes. ${ }^{2,6-8}$ The balance between these regulating molecules determines the extent of tissue vascularization. ${ }^{9}$ The major endogenous inhibitors of angiogenesis include thrombospondin and interferons, ${ }^{10-12}$ whereas the major endogenous promoters of angiogenesis include fibroblast growth factor (FGF), ${ }^{13}$ vascular endothelial growth factor (VEGF), ${ }^{14,15}$ interleukin 8 (IL-8, chemokine (C-X-C motif) ligand 8 (CXCL8)), ${ }^{16,17}$ platelet-derived endothelial cell growth factor ${ }^{18}$ and members of the matrix metalloproteinase family (MMP-2, MMP-9). ${ }^{19}$ In quiescent normal tissues, factors that inhibit angiogenesis predominate, whereas in rapidly dividing tissues (ie, tumors), the balance of angiogenic molecules favors stimulation, creation of neovasculature and tumor growth. ${ }^{3,6}$

Previously, we reported on the increased angiogenic potential of human prostate cancer cells that overexpressed the Bcl-2 proto-oncogene. Specifically, increased $\mathrm{Bcl}-2$ expression enhanced the tumorigenic and angiogenic ability of prostate cancer xenografts. The increased angiogenic potential correlated with increased serum levels of basic FGF (bFGF), IL-8 and MMP-9. ${ }^{20}$ Subsequently, we evaluated human endothelial cells (human umbilical vein endothelial cells (HUVEC) and human dermal microvascular endothelial cells (HDMECs)) cultured in conditioned media from Bcl-2overexpressing human prostate cancer cells. The conditioned media induced increased rates of proliferation and the

${ }^{1}$ Cancer Research Institute, MD Anderson Cancer Center Orlando, Orlando, FL, USA and ${ }^{2}$ Nonagen Bioscience Corporation, Orlando, FL, USA Correspondence: Dr CJ Rosser, MD, MBA, FACS, Cancer Research Institute, MD Anderson Cancer Center Orlando, 6900 Lake Nona Boulevard, Orlando, FL 32827, USA. E-mail: charles.rosser@orlandohealth.com 
expression of important antiapoptotic genes/proteins, possibly providing a survival advantage over endothelial cells grown in conditioned media from cancer cells with low Bcl-2 expression. Comparative genomic profiling of the treated and untreated endothelial cells revealed approximately 250 differentially expressed genes ( $P$-value $<0.001)$. CXCL1 was one of several secreted proteins on the list (fold-change 3.96, $P<2.22 \mathrm{E}-16){ }^{21} \mathrm{CXCL} 1$, a secreted growth factor that interacts with the G-protein-coupled receptor CXCR2, plays an important role in inflammation and as a chemoattractant for neutrophils, but little is known regarding its presence and function in human endothelial cells. ${ }^{22,23}$ In this report, we present data that expand on the role of CXCL1 in human endothelial cells inducing angiogenesis.

\section{MATERIALS AND METHODS Cell Lines}

HUVECs and HDMECs (Cambrex, Wakeville, MD, USA) were cultured in EBM-2 basal media supplemented with EGM-2 MV Kit (Lonza, Pittsburg, PA, USA) containing 2\% fetal bovine serum (FBS). Cells were maintained in a standard humidified incubator at $37^{\circ} \mathrm{C}$ in $5 \% \mathrm{CO}_{2}$ and used at passage numbers $5-7$ for the experiments.

\section{Immunoblotting}

Total protein from HUVECs and HDMECs was extracted using a RIPA buffer with Halt Protease Inhibitor Cocktail (Thermo Fisher Scientific, Rockford, IL, USA). Twenty micrograms of total protein was electrophoresed using MiniPROTEAN TGX gels (Bio-Rad Laboratories, Hercules, CA, USA) and transferred onto PVDF membranes. After blocking in Tris-buffered saline containing 5\% skimmed milk, the membrane was incubated overnight with primary antibodies at $4{ }^{\circ} \mathrm{C}$, followed by $1 \mathrm{~h}$ incubation with horseradish peroxidase (HRP)-conjugated secondary antibody. The bound secondary antibody was detected using enhanced chemiluminescence. CXCL1 antibody (ab86436; rabbit polyclonal, dilution 1/1000) and CXCR2 antibody (ab24963; mouse monoclonal, dilution 1/200) were purchased from Abcam (Cambridge, MA, USA). Cyclin D3 (no. 2936; mouse monoclonal, dilution 1/1000), cyclin B1 (no. 4138; rabbit polyclonal, dilution 1/1000), phospho-cdc2 (no. 9111; rabbit polyclonal, dilution 1/1000), p27 Kip1 (no. 3686; rabbit monoclonal, dilution 1/1000) and p21Waf1/CIP1 (no. 2947; rabbit monoclonal, dilution 1/1000) antibodies were purchased from Cell Signaling Technology (Danvers, MA, USA). Cdk4 (sc-32896; mouse monoclonal, dilution 1/1000) antibody was purchased from Santa Cruz Biotechnology (Santa Cruz, CA, USA). $\beta$-Actin (A1978; mouse monoclonal, dilution 1/10 000) antibody (Sigma-Aldrich, St Louis, MO, USA) was used as a loading control for the immunoblots. To detect secreted epidermal growth factor (EGF), culture supernatants from the endothelial cells were collected and concentrated
25 -fold by centrifugation before western blot analysis as described above.

\section{Double Immunofluorescence Staining}

HUVECs and HDMECs were seeded on coverslips in 24-well plates at a density of $2 \times 10^{4}$ cells per well. After $24 \mathrm{~h}$, cells were fixed in $10 \%$ buffered formalin for $10 \mathrm{~min}$ and permeabilized with $0.2 \%$ Tween- 20 for $10 \mathrm{~min}$. Cells were blocked with $1 \%$ bovine serum albumin (BSA) in PBS for $30 \mathrm{~min}$ and incubated with anti-CXCL1 (ab86436; dilution 1/500) and anti-CXCR2 (ab24963; dilution 1/200) antibody overnight at $4{ }^{\circ} \mathrm{C}$. Following three washes in PBS, cells were incubated with Alexa 594-conjugated goat anti-rabbit IgG (for CXCL1) (1:500; Molecular Probes, Eugene, OR, USA) and Alexa 488-conjugated goat antimouse IgG (for CXCR2) (1:500; Molecular Probes) for $30 \mathrm{~min}$ at room temperature. Following washing, coverslips were mounted immediately with Vectashield Mounting Medium with DAPI (Vector Laboratories, Burlingame, CA, USA). Cells were examined by a Nikon Eclipse E400 fluorescent microscopy (Nikon, Melville, NY, USA) and images were captured using Nikon Software.

\section{Measurement of Secreted CXCL1 by Enzyme-Linked Immunosorbent Assay}

HUVECs and HDMECs were plated onto 6-well plates at a density of $2 \times 10^{5}$ cells. After $24 \mathrm{~h}$ incubation, the media were replaced with $2 \mathrm{ml}$ of fresh growth media per well, and then the media were collected at 4,8 and $24 \mathrm{~h}$ and centrifuged to remove dead cells. The concentration of secreted CXCL1 in the culture supernatant was determined by using a human CXCL1 Enzyme-Linked Immunosorbent Assay (ELISA) Kit (DGR00; R\&D Systems, Minneapolis, MN, USA).

\section{Viability Assay}

HUVECs and HDMECs were seeded in 96-well plates at a density of $2 \times 10^{3}$ cells per well and incubated for $24 \mathrm{~h}$ before treatment. Cells were then treated with recombinant human CXCL1 (275-GR; R\&D Systems), anti-CXCL1mouse monoclonal-neutralizing antibody (ab89318; Abcam), antiCXCR2-neutralizing mouse monoclonal antibody (ab24963; Abcam), control IgG (MAB004; R\&D systems), anti-VEGFneutralizing antibody bevacizumab (Avastin; Genentech, South San Francisco, CA, USA), an ERK inhibitor (PD98059; Calbiochem, San Diego, CA, USA) or a GSK-3 $\beta$ inhibitor (TWS119; Cayman Chemical, Ann Arbor, MI, USA) in EBM-2 medium. After $24 \mathrm{~h}$, cell viability was determined by CellTiter-Glo Luminescent cell viability assay (Promega, Madison, WI, USA) according to the manufacturer's instructions. Three independent experiments were performed in triplicate.

\section{Capillary Tube Formation and Disruption Assays}

To assess the tube-forming ability of HUVECs and HDMECs in vitro, growth factor-reduced Matrigel (BD Bioscience, 
Bedford, MA, USA) was allowed to solidify in the wells of a 96-well plate at $37^{\circ} \mathrm{C}$ for $30 \mathrm{~min}$. HUVECs and HDMECs were seeded at a density of $1 \times 10^{4}$ and $1.5 \times 10^{4}$ cells per well, respectively. For capillary tube formation experiments, endothelial cells were resuspended in growth medium with $20 \mu \mathrm{g} / \mathrm{ml}$ of control IgG, $20 \mu \mathrm{g} / \mathrm{ml}$ anti-CXCL1neutralizing antibody or $1 \mathrm{mg} / \mathrm{ml}$ of bevacizumab before seeding on Matrigel. Photomicrographs of the center of each well were captured using Leica DMIL inverted microscopy (Leica Microsystems AG, Wetzlar, Germany) at $4 \mathrm{~h}$ after seeding (original magnification, $\times 200$ ). For capillary tube disruption experiments, cells were resuspended in growth medium without drugs and seeded and allowed to grow on Matrigel for $4 \mathrm{~h}$ before the initiation of drug treatment. At $2 \mathrm{~h}$ after the addition of $20 \mu \mathrm{g} / \mathrm{ml}$ of control IgG, $20 \mu \mathrm{g} / \mathrm{ml}$ of anti-CXCL1 antibody or $1 \mathrm{mg} / \mathrm{ml}$ of bevacizumab, images of vessels were captured. The antiangiogenic and vascular-disrupting activities of the antibodies were quantitatively evaluated by measuring the total tube length of capillary tubes in four fields from four different wells. In both experiments, cells were constantly maintained at $37^{\circ} \mathrm{C}$ and $5 \% \quad \mathrm{CO}_{2}$. Three independent experiments were performed in triplicate.

\section{Cell Cycle Analysis}

HUVECs and HMVECs were seeded in 6-well plates at a density of $2 \times 10^{5}$ cells per well. After incubation of $24 \mathrm{~h}$, cells were treated with control IgG $(20 \mu \mathrm{g} / \mathrm{ml})$, anti-CXCL1neutralizing antibody $(20 \mu \mathrm{g} / \mathrm{ml})$ or bevacizumab $(1 \mathrm{mg} / \mathrm{ml})$ in growth medium for $24 \mathrm{~h}$. Cells were harvested and fixed with $70 \%$ ethanol overnight in $-20^{\circ} \mathrm{C}$. Cells were suspended in propidium iodide (PI) staining buffer containing $50 \mu \mathrm{g} / \mathrm{ml}$ PI and $200 \mu \mathrm{g} / \mathrm{ml}$ RNase A, and incubated in $37^{\circ} \mathrm{C}$ for $15 \mathrm{~min}$. PI fluorescence was determined by flow cytometry using a FACSCalibur and CellQuest software for acquisition. Cell cycle phase distribution was analyzed and reported by using FlowJo software. Three independent experiments were performed in triplicate.

\section{Scratch Wound Healing Assay}

HUVECs and HMVECs were seeded in 24-well plates at a density of $6 \times 10^{4}$ cells per well and incubated for $24 \mathrm{~h}$. Confluent monolayers were scratched using a $20-\mu$ l pipette tip and rinsed with PBS. Control $\operatorname{IgG}(20 \mu \mathrm{g} / \mathrm{ml})$, antiCXCL1-neutralizing antibody $(20 \mu \mathrm{g} / \mathrm{ml})$ or bevacizumab $(1 \mathrm{mg} / \mathrm{ml})$ was added to the wells in fresh growth medium. The cells in denuded area were monitored at $0,4,8,24$ and $48 \mathrm{~h}$ by phase-contrast microscopy. Images of the defined area were aligned and the migration activity of endothelial cells was quantified as the area of migrating cells into the denuded area. Four images were captured for each treatment and the mean rate of the area of migrating cells over time was compared. Three independent experiments were performed in triplicate.

\section{Intracellular Signaling Array}

In CXCL1 signaling array experiments, HUVECs and HDMECs were treated with $20 \mu \mathrm{g} / \mathrm{ml}$ of control IgG or $20 \mu \mathrm{g} /$ $\mathrm{ml}$ of anti-CXCL1 monoclonal antibody for $24 \mathrm{~h}$ in growth medium. For CXCL1 stimulation experiments, EBM-2 medium was devoid of FBS and growth factors for $18 \mathrm{~h}$, and then cells were treated with or without $100 \mathrm{nM}$ of recombinant CXCL1 for $6 \mathrm{~h}$. Cells were lysed in Cell Lysis Buffer (Cell Signaling Technology). Cell lysates were analyzed using the PathScan Intracellular Signaling Array Kit (Catalog no. 7323S; Cell Signaling Technology) for the simultaneous detection of 18 important and well-characterized phosphorylated signaling molecules. Briefly, the lysates were diluted to $200 \mu \mathrm{g} / \mathrm{ml}$, and $75 \mu \mathrm{l}$ of lysate was added to nitrocellulose-coated glass slides precoated with primary antibodies. The plate was incubated overnight at $4{ }^{\circ} \mathrm{C}$, followed by exposure to the detection antibody cocktail for $1 \mathrm{~h}$ at room temperature. Next, HRPconjugated secondary antibody was added and the plate was incubated for $30 \mathrm{~min}$ at room temperature. Lastly, substrate was added and chemiluminescent signals were detected.

\section{RNA Preparation and RT2 Profiler PCR Arrays}

HUVECs were treated with anti-CXCL1 monoclonal antibody or recombinant CXCL1 as previously described above for the Intracellular Signaling Array experiments. Total RNA was isolated using RNeasy Mini Kit (Qiagen, Valencia, CA, USA) with an on-column DNase digestion step. cDNA was synthesized from $500 \mathrm{ng}$ of total RNA using RT2 Profiler PCR Array First Strand Kit (SABiosciences, Frederick, MD, USA) according to the manufacturer's protocol. $\mathrm{RT}^{2}$ Profiler 'human angiogenesis' PCR arrays (PAHS-024ZA; SABiosciences) were analyzed according to the manufacturer's instructions using an ABI 7300 Real-Time PCR system (Applied Biosystems, Foster City, CA, USA) and ABI 7300 Sequence Detection System software. The specificity of the SYBR Green assay was confirmed by melting-curve analysis and gene expression levels were normalized to housekeeping control gene targets.

\section{Matrigel Plug Assay}

Matrigel plug assay was conducted as described previously. ${ }^{24-28}$ Briefly, six-week-old male athymic nude mice $(\mathrm{Balb} / \mathrm{c})$ were purchased from Charles River Laboratories (Wilmington, MA, USA). Mice were maintained in accordance with the Institutional Animal Care and Use Committee procedures and guidelines. High concentration Matrigel (BD Bioscience) was mixed with $200 \mathrm{ng} / \mathrm{ml}$ of recombinant VEGF (PROSPEC, East Brunswick, NJ, USA). Next, VEGF-containing Matrigel was mixed with either $50 \mu \mathrm{g} / \mathrm{ml}$ of control $\operatorname{IgG}(n=10$ mice), $50 \mu \mathrm{g} / \mathrm{ml}$ of anti-CXCL1-neutralizing antibody ( $n=10$ mice) or $50 \mu \mathrm{g} / \mathrm{ml}$ of bevacizumab ( $n=10$ mice). A total of $500 \mu \mathrm{l}$ of the Matrigel mixture was subcutaneously injected into the lateral dorsal region of 10 mice for each treatment group. At 7 days after implantation, mice were killed and Matrigel plugs were resected, stained with hematoxylin and eosin and photographed. 
To identify infiltrating endothelial cells in Matrigel plugs, immunofluorescence staining was performed with an antibody specific to endothelial cell (CD31). Briefly, Matrigel plugs were embedded in OCT compound (Tissue Tek; Miles Laboratories, Naperville, IL, USA), and frozen in liquid nitrogen. Frozen sections were placed on glass slides, fixed with $4 \%$ paraformaldehyde and rinsed three times, followed by blocking in $1 \%$ BSA for $1 \mathrm{~h}$. The sections were incubated in anti-CD31 goat polyclonal antibody (sc-1506; dilution 1/200; Santa Cruz Biotechnology) and anti-CXCL1 rabbit polyclonal antibody for $1 \mathrm{~h}$ in room temperature and rinsed three times. The sections were incubated in Alexa Fluor 488 anti-goat IgG and Alexa Fluor 594 anti-rabbit IgG secondary antibody (dilution 1/500; Molecular Probes) and mounted with Mounting Medium with DAPI. The sections were examined by fluorescent microscopy and images were captured. Formation of functional blood vessels within the Matrigel plug was quantified as described previously. ${ }^{26,29}$ In addition, the content of hemoglobin $(\mathrm{Hb})$ in each plug was measured using Drabkin's reagent, Brij L23 solution and $\mathrm{Hb}$ from bovine blood according to the manufacturer's protocol (Sigma-Aldrich; catalog no. D5941). Briefly, resected Matrigel plugs were homogenized in $500 \mu \mathrm{l}$ of RBC lysis buffer on ice and cleared by centrifugation at $200 \mathrm{~g}$ for $6 \mathrm{~min}$ at $4{ }^{\circ} \mathrm{C}$. The supernatant was collected and used in triplicate to measure $\mathrm{Hb}$ content.

\section{Statistical Analyses}

All data are expressed as mean \pm standard deviation (s.d). Student's $t$-test or Mann-Whitney $U$-test was applied for statistical analysis. In addition, for our Matrigel plug assay sample size calculations we assumed that the mean number of blood vessels will equal the median and that $\mathrm{Hb}$ content will have a normal distribution for each treatment group. Furthermore, because we will make multiple comparisons among the various treatment groups, we will use the conservative Bonferroni correction to the significance level to adjust for multiple comparisons. Therefore, our significance level for each comparison is $0.05 / 3=0.017$. To ensure that we are able to detect the differences for each of the possible treatment comparisons, we must have 10 Matrigel plugs per treatment group, which will yield at least $90 \%$ power with an overall significance level of $<0.05$ to detect the expected treatment differences in the number of blood vessels with two-sided two-sample $t$-tests. Data were analyzed and figures were drawn using GraphPad Prism 5.0 (San Diego, CA, USA). $P$-value $<0.05$ was considered significant.

\section{RESULTS}

\section{CXCL1 Modulates Endothelial Cell Behavior}

We have shown that human endothelial cells subjected to conditioned media from Bcl-2-expressing human cancer cells acquire a unique genomic signature, which may in part aid with tumor growth and angiogenesis. One of the differentially expressed genes of note that has not been extensively studied in endothelial cells from tumors was CXCL1 (fold-change of $3.98 P<2.22 \mathrm{E}-16$ ). In this study, we set out to explore the potential role of CXCL1 in human endothelial cell phenotype and angiogenesis. Western blot analysis showed that both CXCL1 and its receptor CXCR2 are present in HUVECs and HDMECs (Figure 1a). Immunofluorescence staining demonstrated colocalization of CXCL1 and CXCR2 in HUVECs and HDMECs (Figure 1b). Next, to determine the CXCL1 level secreted to the cultured media, ELISA was performed on conditioned media from HUVECs and HDMECs. Although CXCL1 was undetectable in the fresh media, secreted CXCL1 level increased in a time-dependent manner (Figure 1c), which has not been reported with VEGF. $^{23}$ Using a series of CellTiter-Glo Luminescent cell viability assays, we demonstrated that recombinant CXCL1 sustained cellular viability, and interference of the CXCL1/ CXCR2 interaction with an anti-CXCR2 antibody blocks this induction (Figure 1d). Furthermore, targeting CXCL1 with a neutralizing antibody at low levels $(10-20 \mu \mathrm{g} / \mathrm{ml})$ resulted in reduced rates of cellular viability in both HUVECs and HDMECs in a dose-dependent manner. In contrast, only a high dose $(1000 \mu \mathrm{g} / \mathrm{ml})$ of bevacizumab, a clinically used monoclonal antibody that inhibits VEGF from binding with its receptor, was associated with a reduction in viability of HUVECs (Figure 1e). Utilizing the CXCL1-neutralizing antibody strategy, we were also able to inhibit the formation of capillary vessels in an in vitro tube formation assay. Human endothelial cells were plated on Matrigel-coated plates with $20 \mu \mathrm{g} / \mathrm{ml}$ of control IgG, $20 \mu \mathrm{g} / \mathrm{ml}$ of anti-CXCL1 antibody or $1 \mathrm{mg} / \mathrm{ml}$ of bevacizumab and incubated for $4 \mathrm{~h}$ to allow endothelial tube formation. Reduction of tube formation was more pronounced in experiments with CXCL1-neutralizing antibody compared with bevacizumab. Specifically, the percentage of tube length in HUVEC cells treated with CXCL1-neutralizing antibody or bevacizumab was 27 and $59 \%$, respectively, relative to untreated and $\operatorname{IgG}$ controls (Figure 1f). The additional reduction observed with CXCL1neutralizing antibody compared with bevacizumab was significant $(P=0.029)$. Similar effects were apparent with HDMECs. The percentage tube length was $13 \%$ with CXCL1neutralizing antibody and $46 \%$ with bevacizumab relative to controls, and again the reduction observed with CXCL1neutralizing antibody relative to bevacizumab was significant $(P=0.029)$ (Figure 1f). We also assessed whether the CXCL1 interference strategy could disrupt cords of endothelial cells by adding the neutralizing antibodies $4 \mathrm{~h}$ after plating on Matrigel. No significant disrupting effects were observed (Figure $1 \mathrm{~g}$ ), supporting a primary role of CXCL1 in the formation of new vessels.

Interference of CXCL1 Results in the G1-Phase Arrest of
Endothelial Cells and a Reduction in Migratory Potential As shown in Figures 1d and e, CXCL1-neutralizing antibody reduced the viability of HUVECs and HDMECs. Viability may be reduced through a number of mechanisms, including aberrations in progression through the cell cycle. Next, we 
a

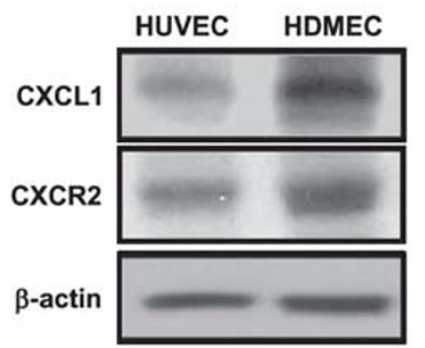

b

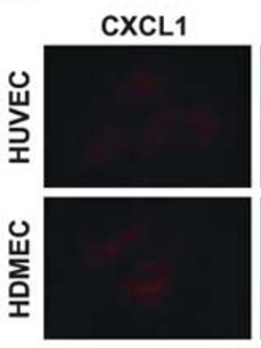

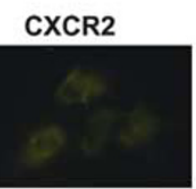

Merge + DAPI
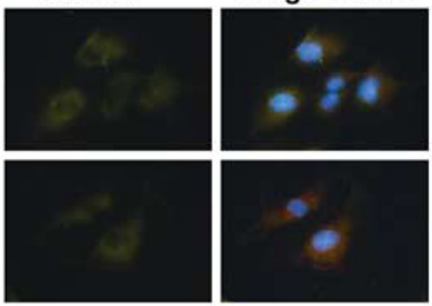

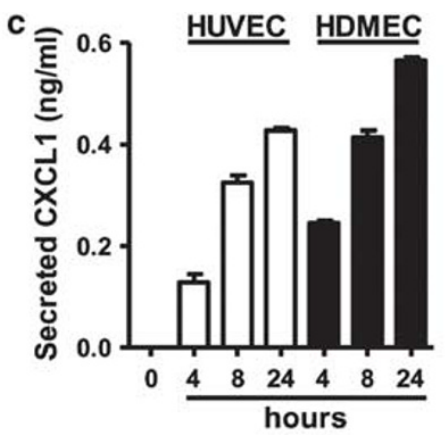

d
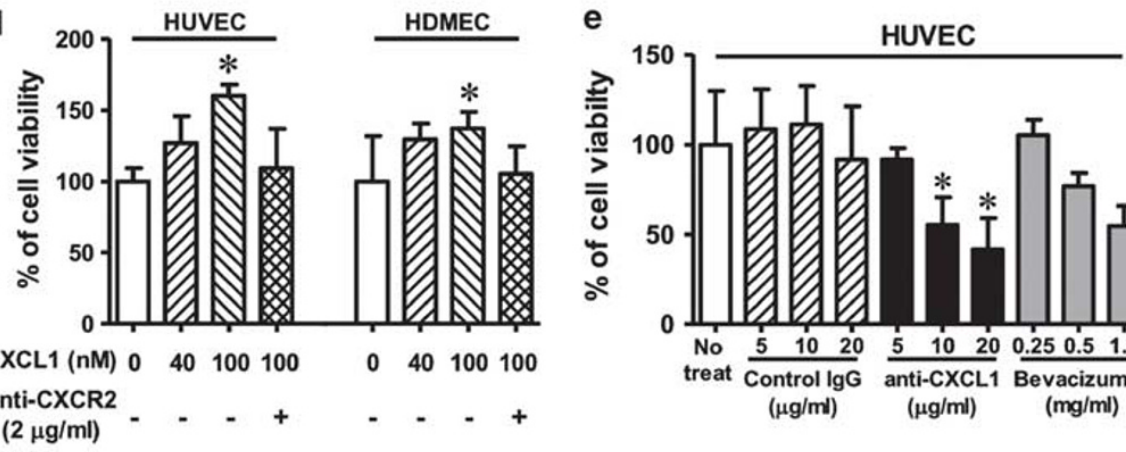

HDMEC

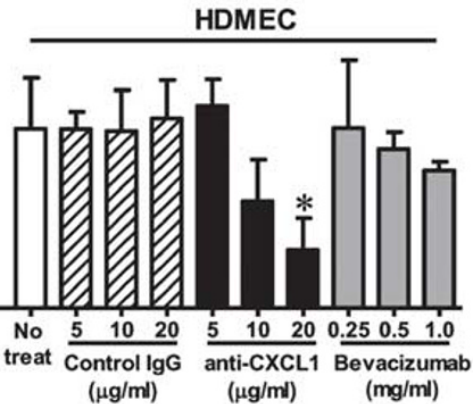

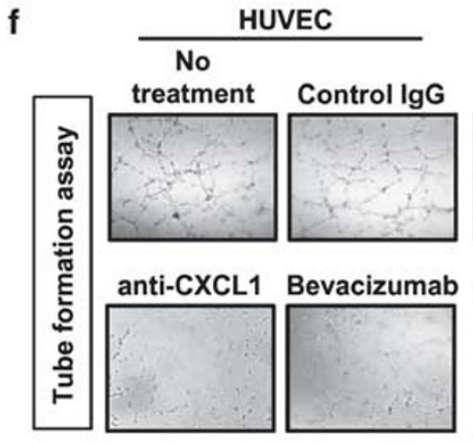

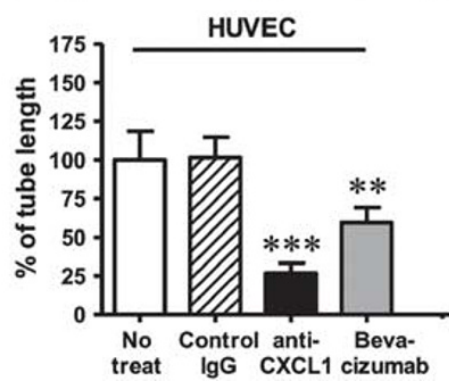

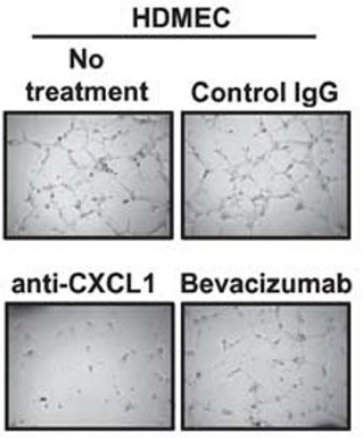

HDMEC

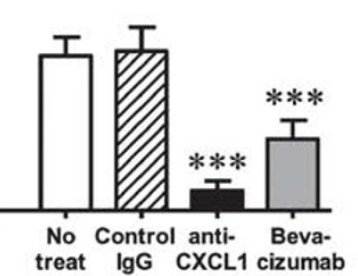

g
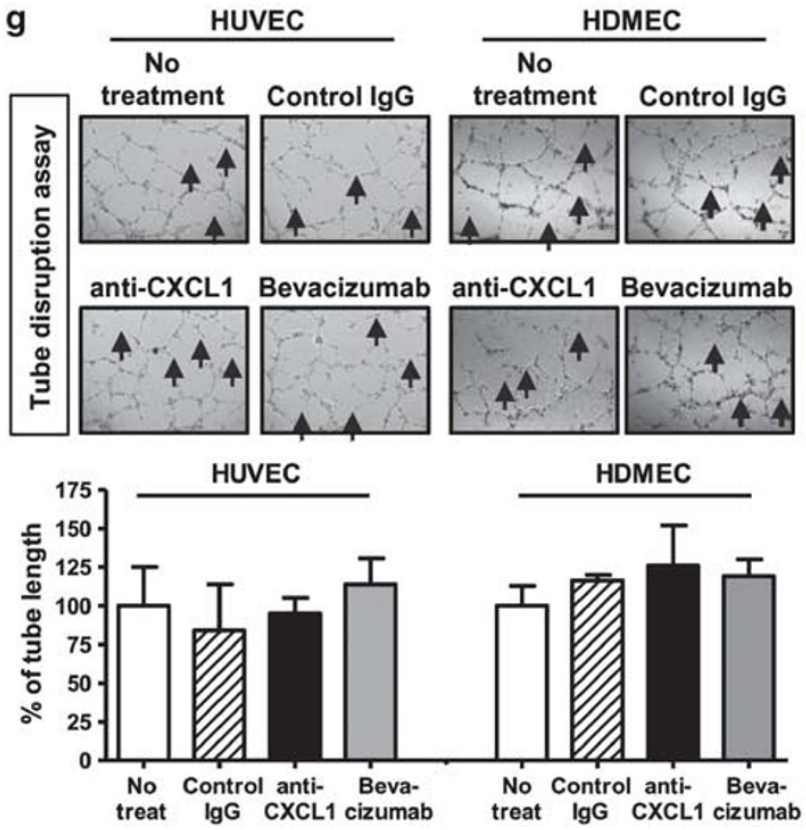

Figure 1 CXCL1 regulates endothelial cell phenotype. (a) Chemokine (C-X-C motif) ligand 1 (CXCL1) and CXCR2 are detected in the lysates of human endothelial cells (human umbilical vein endothelial cells (HUVECs) and human dermal microvascular endothelial cells (HDMECs)) by western blot analysis. (b) Immunofluorescence staining demonstrates colocalization of CXCL1 and CXCR2 in HUVECs and HDMECs. Original magnification, $\times 400$. (c) Time-course analysis of CXCL1 secretion from two endothelial cells was performed. Cells were plated onto 6 -well plate of a density of $2 \times 10^{5}$ cells. After $24 \mathrm{~h}$ incubation, the media were replaced with fresh growth media per well. Next, the media were collected at 4,8 and $24 \mathrm{~h}$ and subjected to enzyme-linked immunosorbent assay (ELISA). Data are presented as mean \pm s.d. (d) Recombinant human CXCL1 supported endothelial cell viability, and this effect is blocked by neutralizing antibodies to CXCR2 $(2 \mu \mathrm{g} / \mathrm{ml})$. Cell viability (\%) is expressed by relative values to controls. Data from one representative experiments are presented as mean \pm s.d., ${ }^{*} P<0.05$. (e) Neutralizing antibodies to $C X C L 1$ reduced cellular viability. Cell viability (\%) is expressed by relative value to controls. Data from one representative experiments are presented as mean \pm s.d., ${ }^{*} P<0.05$. (f) Neutralizing CXCL1 antibody inhibited the ability of endothelial cells to form capillary tubes in vitro. Photographs show form capillary tubes of no treatment, control lgG, anti-CXCL1 and bevacizumab. Data from one representative experiment are presented as mean \pm s.d., ${ }^{* *} P<0.01$, ${ }^{* * *} P<0.001$, original magnification, $\times$ 200. (g) Neutralizing CXCL1 antibody do not disrupt established endothelial cells tube formation. Arrows show disrupted points. Data from one representative experiment are presented as mean \pm s.d., original magnification, $\times 200$. DAPI, 4',6-diamidino-2-phenylindole. 
evaluated cellular DNA content for the estimation of cell cycle phase distribution. Targeting CXCL1 resulted in a slight G1-phase arrest in both HUVECs and HDMECs, without a change in the G2/M phase (Figure 2a). These findings were validated by western blot analysis, where we demonstrated a reduction in cyclin D3 and cdk4 expression, and an increase in p27 Kip1 expression. CyclinD3, cdk4 and p27 Kip1 are important proteins in the G1-phase progression, whereas key proteins in the G2/M phase (cyclin B1, cdc2 and p21 Cip1) were unchanged (Figure 2b). Although bevacizumab was noted to cause a reduction in cellular viability, this reduction in viability was not associated with changes in cell cycle.

Using a scratch wound healing assay, a reduction in the migratory potential of both HUVECs and HDMECs was observed when CXCL1-neutralizing antibodies or bevacizumab were present (Figure 2c). In HUVEC cells, the inhibitory effect of CXCL1-neutralizing antibodies and bevacizumab was similar (55 vs $49 \%$, respectively, $P=0.32$ ), a
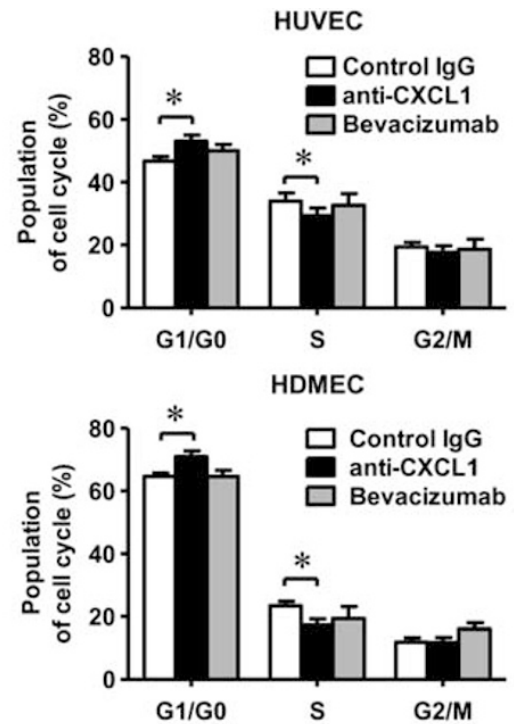

C
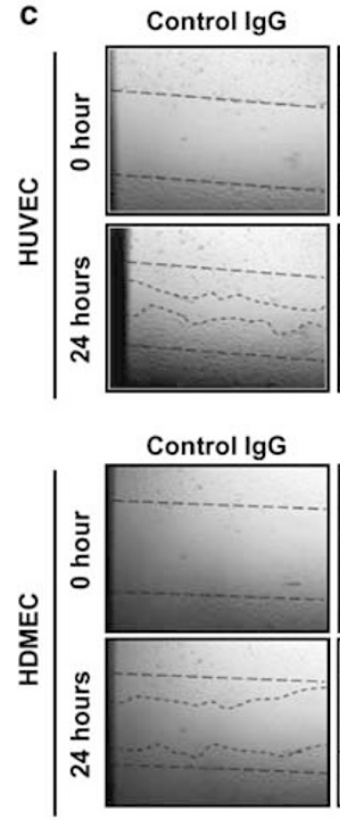

b
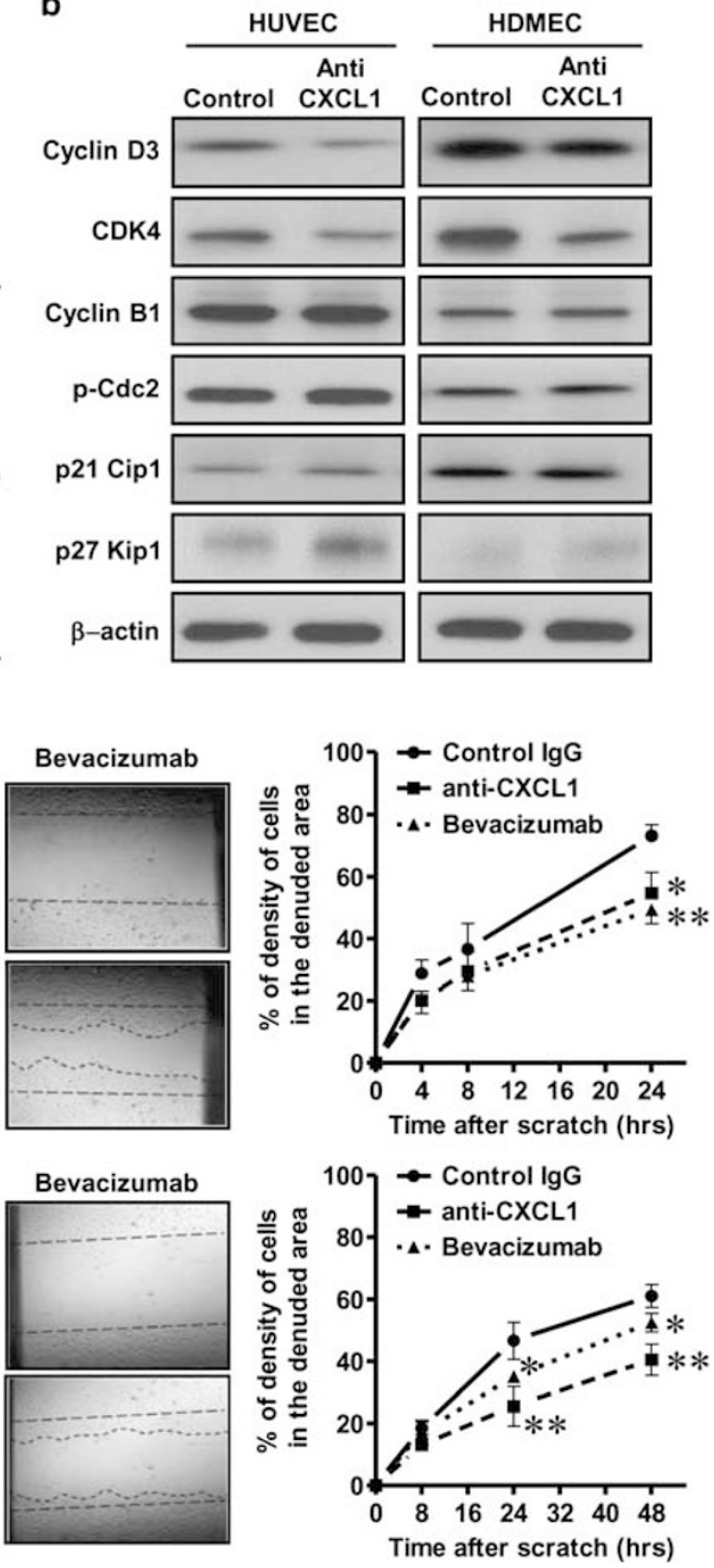

Figure 2 Chemokine (C-X-C motif) ligand 1 (CXCL1) interference causes the G1-phase arrest and reduction in migratory potential. (a) Flow cytometry with propidium iodide (PI) staining was used to evaluate cellular DNA content for the estimation of cell cycle phase distribution. Targeting CXCL1 resulted in a trend to the G1-phase arrest. Data from one representative experiments are presented as mean \pm s.d., ${ }^{*} P<0.05$. (b) Lysates of human endothelial cells were subjected to western blot analysis for cyclin D3, cdk4, cyclin B1, cdk2, p21 and p27. The G1-phase arrest was validated by corresponding changes in cyclin D, cdk4 and p27/Kip1. (c) Using a scratch wound healing assay, a reduction in migratory potential of both HUVECs and HDMECs was observed with CXCL1-neutralizing antibodies and bevacizumab. Data from one representative experiment are presented as mean \pm s.d., ${ }^{*} P<0.05,{ }^{* *} P<0.01$, original magnification, $\times 200$. lgG, immunoglobulin $\mathrm{G}$. 
but in HDMEC cells, the inhibitory effect was more pronounced with CXCL1-neutralizing antibody treatment compared with bevacizumab (38 vs 53\%, respectively, $P=0.003)$.
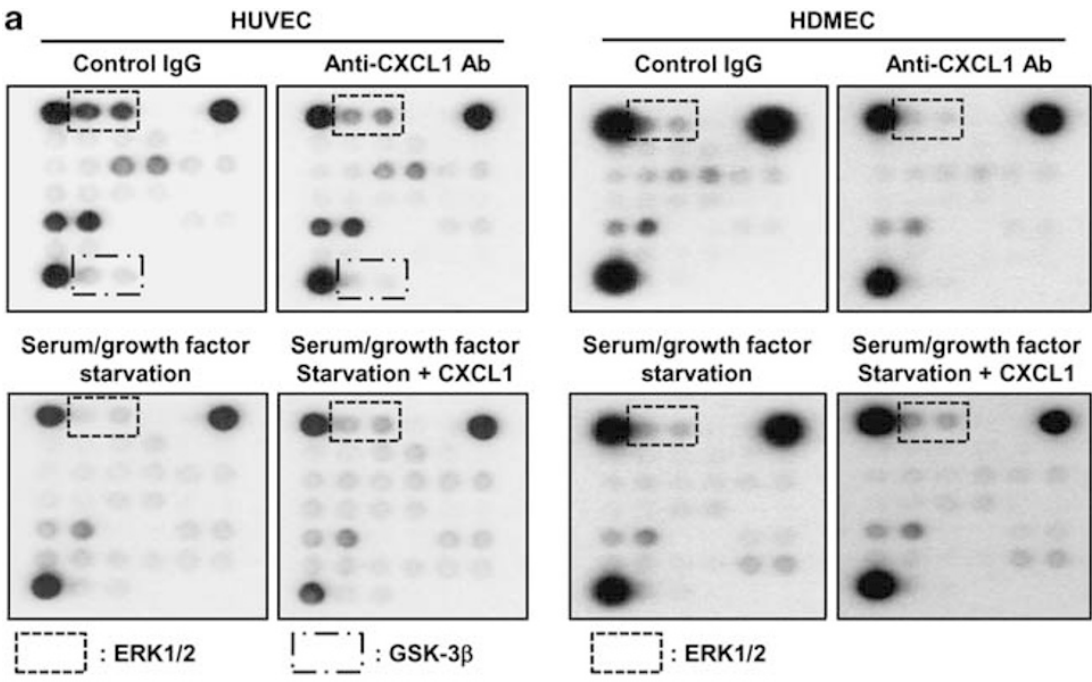

b

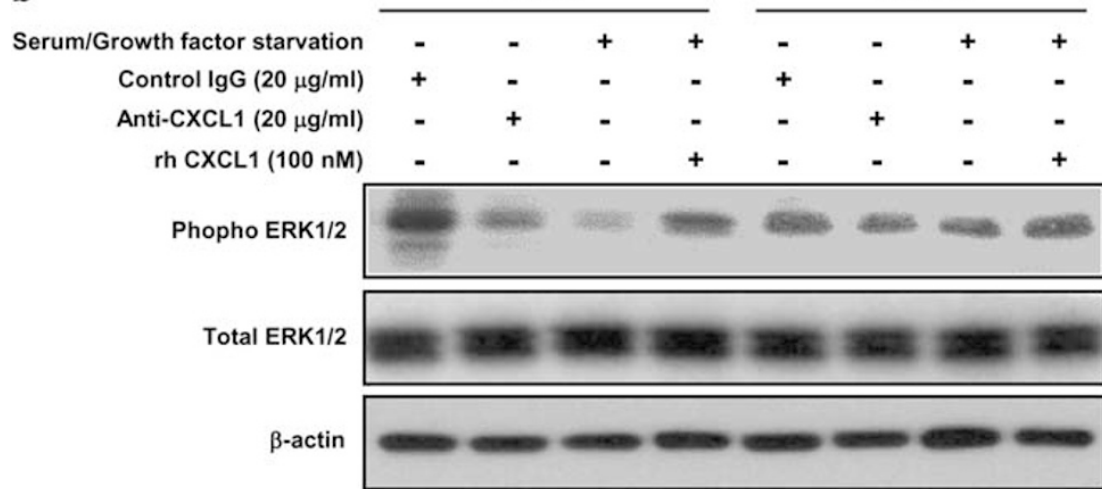

c

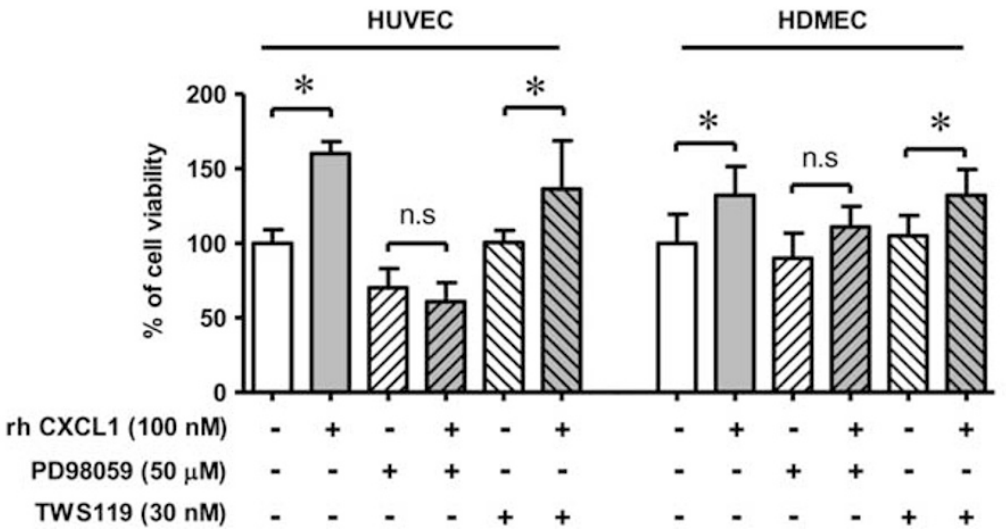

Figure 3 Chemokine (C-X-C motif) ligand 1 (CXCL1) effects are associated with extracellular-signal-regulated kinase (ERK)1/2 signaling. (a) The phosphorylation status of 18 important signaling proteins was monitored by array hybridization. Modulation of CXCL1 was associated with ERK1/2 in both human umbilical vein endothelial cells (HUVECs) and human dermal microvascular endothelial cells (HDMECs). (b) Western blot analysis shows that the phosphorylation levels of ERK1/2 were reduced when CXCL1 stimulation was absent. Blots were performed three times with similar results. (c) Targeting of ERK1/2 resulted in reduction in cellular viability. PD98059, a mitogen-activated protein kinase kinase (MEK) inhibitor; TWS119, a glycogen synthase kinase $3 \beta(G S K-3 \beta)$ inhibitor. Data from one representative experiment are presented as mean \pm s.d., $* P<0.05$. Ab, antibody; lgG, immunoglobulin G; NS, nonsignificant; rh, recombinant human. 
exerts its cellular effects through ERK signaling alone. ${ }^{31}$ We used the PathScan Intracellular Signaling Array Kit to monitor the expression of 18 signaling molecules that are phosphorylated in response to signal-transduction pathway activation. Treatment of both HUVECs and HDMECs with recombinant CXCL1 resulted in an increase in ERK1/2 signaling, and interference of CXCL1 function with neutralizing antibodies caused a corresponding decrease in phosphorylation of ERK1/2 (Figure 3a). Western blot analysis confirmed that cellular phosphorylation levels of ERK1/2 were reduced when CXCL1 stimulation was absent (Figure $3 \mathrm{~b}$ ). No major differences in GSK-3 $\beta$ phosphorylation were observed in these experiments via confirmatory western blots (data not shown). Both HUVECs and HDMECs were treated with the ERK1/2 inhibitor, PD98059 and the GSK- $\beta$ inhibitor, TWS119, before analysis by viability assay. In HUVECs, PD98059 $(50 \mu \mathrm{M})$ blocked the increase in cellular viability seen with exposure to CXCL1, and further reduced total cellular viability (Figure 3c). In HDMECs, PD 98059 also blocked the increased cellular viability seen with exposure to CXCL1, but only returned cells to the unstimulated state (Figure 3c). Targeting GSK- $\beta$ was not associated with changes in cellular viability in either cell line.

\section{CXCL1 Regulates Endothelial EGF Levels}

After demonstrating that targeting CXCL1 can inhibit angiogenesis (Figure 1f), we set out to evaluate which angiogenic factors may have a role in this setting using the Human Angiogenesis-PCR Array. As expected, the expression of numerous genes was altered in this experiment. One important gene of interest to us was EGF, a proangiogenic molecule (Figure 4a). Secretion of EGF was elevated in HUVECs and HDMECs treated by recombinant CXCL1 and reduced in HUVECs treated by CXCL1-neutralizing antibodies (Figure 4b).

\section{CXCL1 Regulates Angiogenesis}

To investigate whether CXCL1 has a role in angiogenesis, we used an established xenograft model. Thirty Balb/c mice were injected with $500 \mu \mathrm{l}$ of Matrigel containing recombinant VEGF $(200 \mathrm{ng} / \mathrm{ml})$, with $50 \mu \mathrm{g} / \mathrm{ml}$ of control $\operatorname{IgG}(n=10)$, $50 \mu \mathrm{g} / \mathrm{ml}$ of anti-CXCL1-neutralizing antibody $(n=10)$ or $50 \mu \mathrm{g} / \mathrm{ml}$ of bevacizumab $(n=10)$. After 7 days, Matrigel plugs were resected and stained with hematoxylin and eosin (Figure 5a). Routine evaluation revealed a reduction in vasculature in the Matrigel plugs treated with anti-CXCL1neutralizing antibody and bevacizumab. To confirm the reduction in vasculature, the number of vessels per
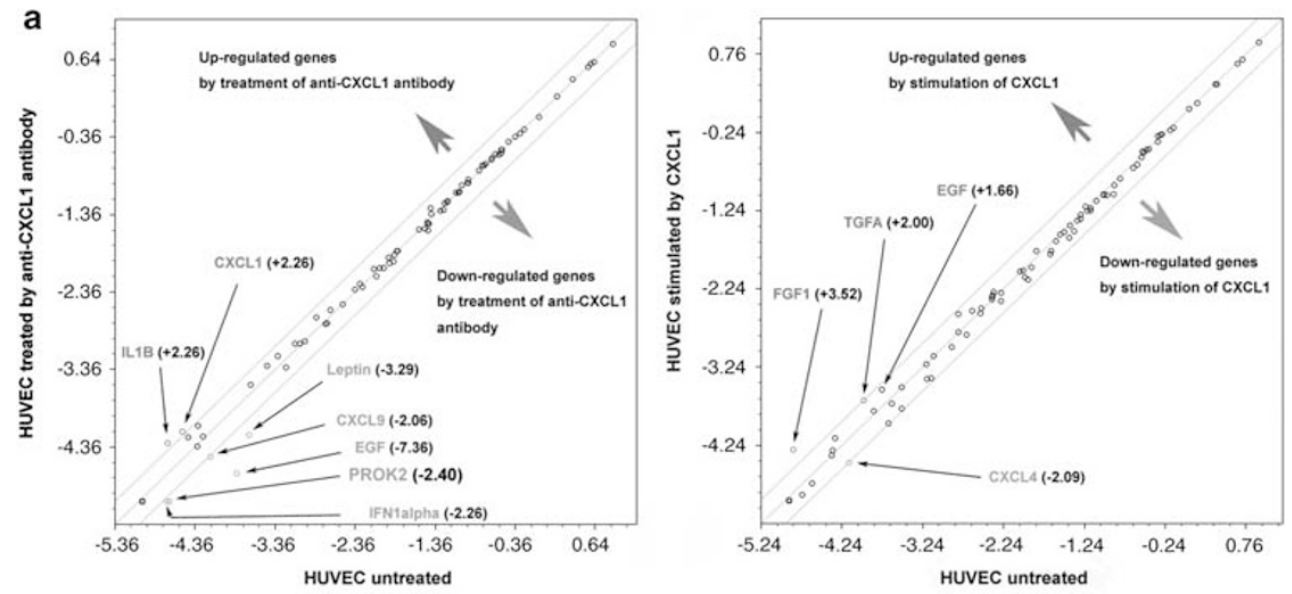

b

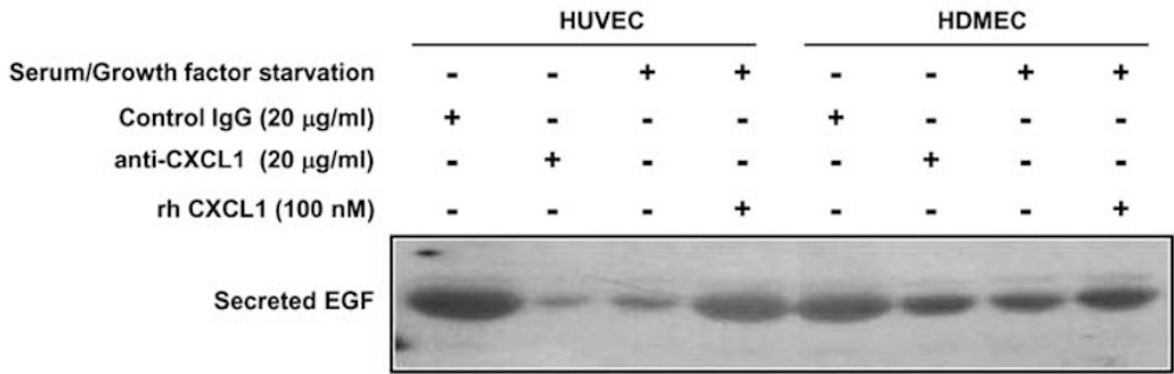

Figure 4 Chemokine (C-X-C motif) ligand 1 (CXCL1) regulates epidermal growth factor (EGF) expression. (a) A polymerase chain reaction (PCR) array was used to assess the expression of 84 genes reportedly related to angiogenesis. Treatment of human umbilical vein endothelial cells (HUVECs) with recombinant human (rh) CXCL1- or CXCL1-neutralizing antibodies altered the expression of several genes, including EGF and CXCL4 (left and right panels). (b) The concentrated conditioned media of HUVECs and human dermal microvascular endothelial cells (HDMECs) subjected to the same treatments was analyzed by western blot. Blots were performed three times with similar results. FGF, fibroblast growth factor; IFN, interferon; IL, interleukin; TGF, tumor growth factor. 
high-power field was counted. The number of vessels was significantly reduced in both the CXCL1-neutralizing antibody group and bevacizumab group compared with the control IgG group (3.4 vs 7.2, $P=0.015$ and $3.6 v s$ 7.2, $P=0.026$, respectively) (Figure 5b). Matrigel plugs were also stained for CD31, which is indicative of migrating endothelial cells. CD31-positive cells were reduced in Matigel plugs treated with CXCL1-neutralizing antibody and bevacizumab (Figure 5b). Another surrogate measure of tissue vasculature is measuring the total $\mathrm{Hb}$ content within the tissue. $\mathrm{Hb}$ from the Matrigel plugs was extracted, subjected to Drabkin's reagent and Brij L23 solution, and analyzed on a spectrophotometer. The $\mathrm{Hg}$ content of Matrigel plug was significantly reduced in the CXCL1-neutralizing antibody group $(0.5$ vs $1.6 \mathrm{mg} / \mathrm{g}, \quad P=0.04)$, but not significantly reduced by bevacizumab (0.8 vs $1.5 \mathrm{mg} / \mathrm{g}, \quad P=0.49)$ (Figure 5c). To confirm CXCL1 expression in endothelial cells in the Matrigle plug, double immunofluorescence staining a
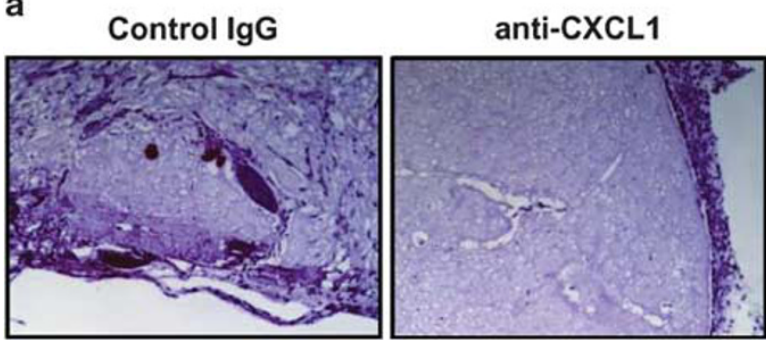

b
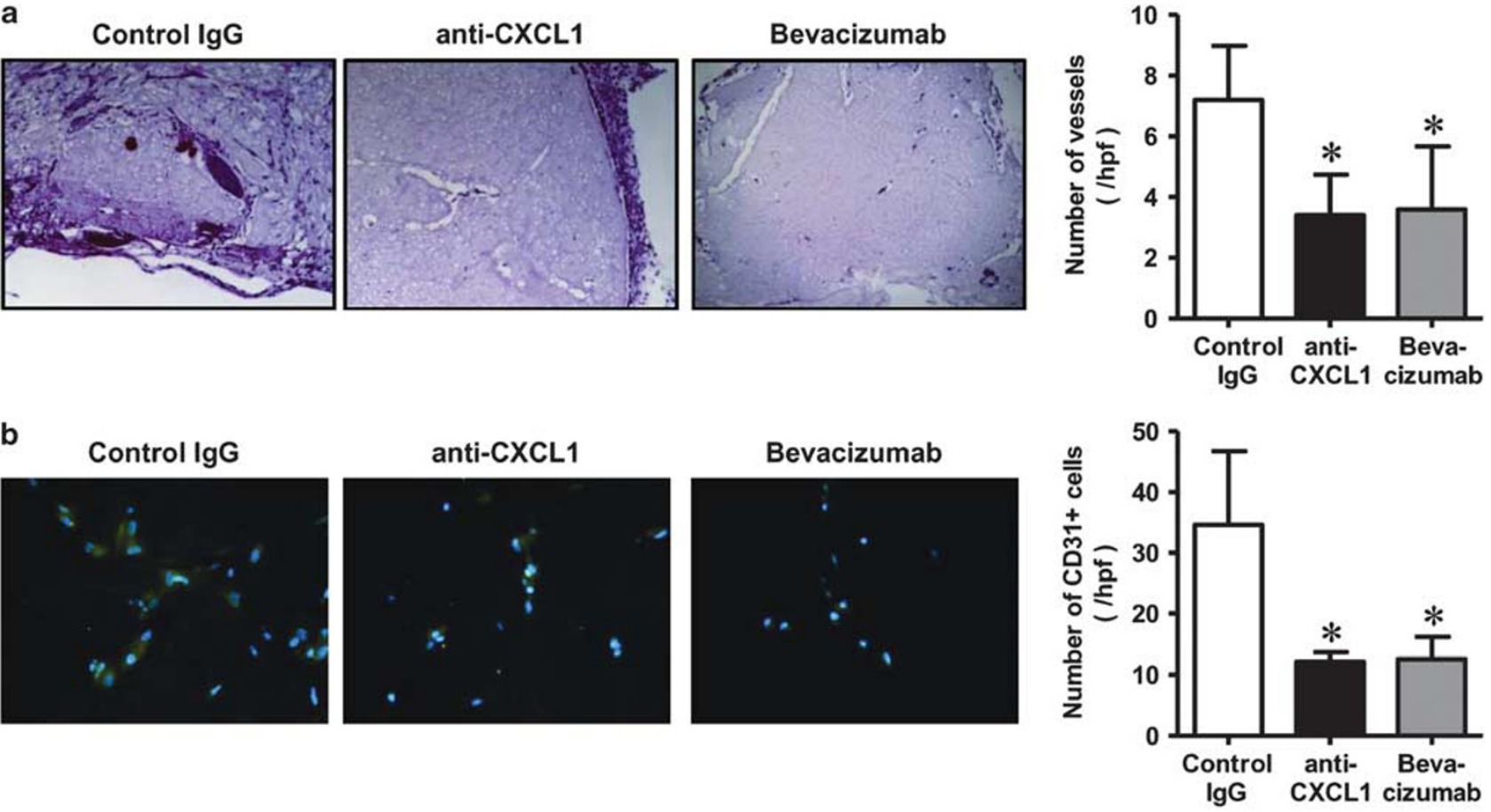

C

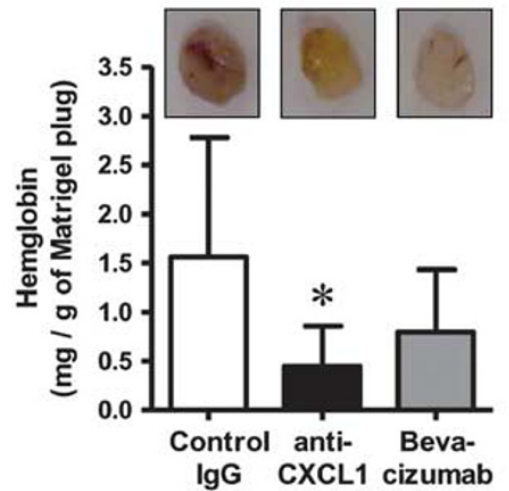

d

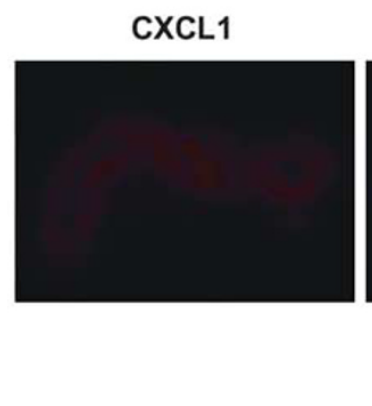

CD31

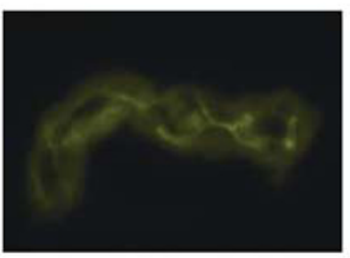

Merge + DAPI

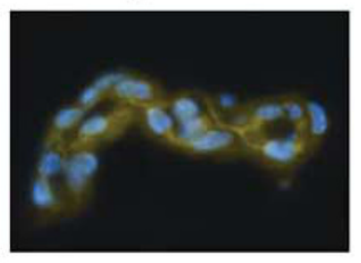

Figure 5 Chemokine (C-X-C motif) ligand 1 (CXCL1) regulates angiogenesis in a xenograft model. (a) Thirty Balb/c mice were injected with $500 \mu$ l of Matrigel containing recombinant vascular endothelial growth factor (VEGF) $(200 \mathrm{ng} / \mathrm{ml})$, plus either $50 \mu \mathrm{g} / \mathrm{ml}$ of control immunoglobulin G (lgG) ( $n=10)$, $50 \mu \mathrm{g} / \mathrm{ml}$ of anti-CXCL1-neutralizing antibody $(n=10)$ or $50 \mu \mathrm{g} / \mathrm{ml}$ of bevacizumab $(n=10)$. After 7 days, Matrigel plugs were resected and stained with hematoxylin and eosin. Vasculature identified on hematoxylin and eosin staining was counted in five random fields. Less vasculature was noted in the both the anti-CXCL1 and bevacizumab groups. ${ }^{*} P<0.05$, original magnification, $\times 100$. (b) The population of endothelial cells within the Matrigel plugs was assessed by anti-CD31 immunofluorescence staining. The number of fluorescent cells was counted per high-power field (hpf). CD31-positive cells were reduced in both the anti-CXCL1 and bevacizumab groups ( $\left.{ }^{*} P<0.05\right)$, original magnification, $\times 400$. (c) The total hemoglobin $(\mathrm{Hb})$ content of the Matrigel plugs was used as another quantifiable surrogate measure of angiogenesis. Hb was extracted from the Matrigel plugs and detected colorimetrically. A significant reduction in $\mathrm{Hb}$ content was evident in the Matrigel plugs treated with anti-CXCL1 antibodies ( $P<0.05)$. (d) Double immunofluorescence staining analysis shows the expression of CXCL1 (red) and CD31 (green) in Matrigel plug from control animals. DAPI, 4',6diamidino-2-phenylindole (DAPI) is used for nuclear counterstain. CD31-positive vascular endothelial cells express CXCL1, original magnification, $\times 1000$. 
analysis was performed. Endothelial cells from control Matrigel plugs were noted to express CXCL1 (Figure 5d).

\section{DISCUSSION}

Chemotactic cytokines, also referred as to as chemokines, are known to be critical mediators of the inflammatory response by regulating recruitment of cells from both the innate and adaptive immune systems to diseased tissues. Dysregulated expression and activity of certain chemokines have been implicated in cancer initiation and progression. Specifically, chronic chemokine exposure is associated with macrophage and T-cell accumulation, chronic activation of macrophages, abnormal angiogenesis and DNA damage due to the presence of reactive oxygen species. ${ }^{32,33}$ Furthermore, chemokines have been known to regulate pivotal processes during tumor progression, including primary tumor growth, tumor angiogenesis and development of metastatic disease. Chemokines may also enhance epithelial-stromal interactions facilitating tumor growth and invasion. ${ }^{34}$ CXCL1 (also known as growth-regulated oncogene- $\alpha$ or melanoma growth stimulatory activity, $\alpha$ ) has been reported to be overexpressed in many cancers. ${ }^{35,36}$ However, its presence has also been negatively associated with cancers, ${ }^{37}$ attesting to its complex role in tumorigenesis and angiogenesis. Little information is available describing CXCL1 expression and function in human endothelial cells associated with tumors. Warner et al. ${ }^{38}$ reported that CXC chemokines (specifically CXCL1) secreted by endothelial cells induce tumor cell invasion and then suggested that the process of lateral spread of tumor cells observed in tumorigenesis is guided by chemotactic signals that originated from endothelial cells, which is in line with our findings.

Herein, we demonstrated that CXCL1 stimulates human endothelial cells and increases rates of angiogenesis. Blockade of CXCL1 with a neutralizing antibody resulted in the reduction of human endothelial cell viability and negated its ability to induce angiogenesis. We went on to demonstrate that the CXCL1 effects require interaction with its receptor CXCR2, involves the ERK1/2 signaling pathway and leads to the expression and secretion of EGF, a potent stimulator of angiogenesis. Though ERK 1/2 signaling is held to be the predominant mode of CXCL1 signaling, other researchers have implicated the MEKK1/p38 mitogen-activated protein kinase signaling pathway in CXCL1 stimulation. ${ }^{39,40}$ Ultimately, we revealed in a xenograft model that CXCL1 regulates endothelial vessel formation.

CXCL1 possesses similar characteristics to CXC chemokine 8 with respect to angiogenesis. Initially, IL- 8 was shown to selectively stimulate chemotactic activity for neutrophils and lymphocytes, ${ }^{41,42}$ but subsequent studies revealed that IL- 8 is multifunctional, inducing angiogenesis, ${ }^{43,44}$ migration $^{45}$ and proliferation. ${ }^{46}$ IL-8 is produced by a wide range of cells, including lymphocytes, monocytes, endothelial cells, fibroblasts, hepatocytes and keratinocytes, allowing IL-8 to act as an autocrine growth factor or an angiogenic factor. ${ }^{46,47}$
We have demonstrated that CXCL1 is produced by endothelial cells and by various epithelial cells, including human bladder cancer cells and human prostate cancer cell line (data not shown). It is feasible that endothelial cells' CXCL1 also has a role as a paracrine $e^{38,48}$ and autocrine growth factor, and like IL-8 may have wide-ranging influence on angiogenic and even metastatic propensity. Additional studies are underway to investigate the potential cross-talk between CXCL1 and IL-8, and a possible correlation between angiogenesis and CXCL1 expression within disease states.

In this study, we demonstrate that vasculature could express CXCL1, which could then via autocrine response further stimulate angiogenesis as well as support the growth of surrounding epithelial tissue via a paracrine response. In addition, we further characterize the mechanism by which CXCL1 affects vasculature. A better understanding of the role of CXCL1 in the interactions between the endothelial and epithelial components will provide insight into how human tissues use CXCL1 to survive and thrive in a hostile environment.

\section{DISCLOSURE/CONFLICT OF INTEREST}

Drs Goodison and Rosser are employees of Nonagen Bioscience Corporation. The authors declare no conflict of interest.

1. Folkman J. Angiogenesis in cancer, vascular, rheumatoid, and other diseases. Nat Med 1985;1:27-31.

2. Folkman J, Klagsbrun M. Angiogenic factors. Science 1987;235: 442-447.

3. Hanahan D, Folkman J. Patterns and emerging mechanisms of the angiogenic switch during tumorigenesis. Cell 1996;86:353-364.

4. Liotta LA, Kleinerman J, Saidel GM. Quantitative relationships of intravascular tumor cells, tumor vessels, and pulmonary metastases following tumor implantation. Cancer Res 1974;34:997-1003.

5. Weidner N, Folkman J, Pozza F, et al. Tumor angiogenesis: a new significant and independent prognostic indicator in early stage breast carcinoma. J Natl Cancer Inst 1992;84:1875-1887.

6. Bochner BH, Cote RJ, Weidner N. Angiogenesis in bladder cancer: relationship between microvessel density and tumor prognosis. J Natl Cancer Inst 1995;87:1603-1612.

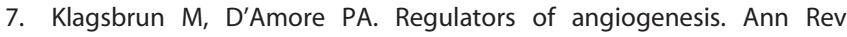
Physiol 1991;53:217-239.

8. Liotta LA, Steeg PS, Stetler-Stevenson WG. Cancer metastasis and angiogenesis: an imbalance of positive and negative regulation. Cell 1991;64:327-336.

9. Blood $\mathrm{CH}$, Zetter BR. Tumor interactions with the vasculature: angiogenesis and tumor metastasis. Biochem Biophys Acta 1990;1032:89-118.

10. Grossfeld GD, Ginsberg DA, Stein JP. Thrombospondin-1 expression in bladder cancer: association with p53 alterations, tumor angiogenesis, and tumor progression. J Natl Cancer Inst (Bethesda, MD) 1997;89:219-227.

11. Folkman J, Ingber D. Inhibition of angiogenesis. Semin Cancer Biol 1992;3:89-96.

12. Sidky YA, Borden EC. Inhibition of angiogenesis by interferons: effects on tumor- and lymphocyte-induced vascular responses. Cancer Res 1987:47:5155-5161.

13. O'Brien T, Cranston D, Fuggle $S$, et al. Two mechanisms of basic fibroblast growth factor-induced angiogenesis in bladder cancer 1997). Cancer Res, 57:136-140.

14. Köllermann J, Helpap B. Expression of vascular endothelial growth factor (VEGF) and VEGFreceptor Flk-1 in benign, premalignant, and malignant prostate tissue. Am J Clin Pathol 2001;116:115-121.

15. Ferrara N, Davis-Smyth T. The biology of vascular endothelial growth factor. Endocr Rev 1997;18:4-25. 
16. Inoue K, Slaton JW, Eve BY, et al. Interleukin 8 expression regulates tumorigenicity and metastases in androgen-independent prostate cancer. Clin Cancer Res 2000;6:2104-2119.

17. Uehara $H$, Troncoso $P$, Johnston $D$, et al. Expression of interleukin-8 gene in radical prostatectomy specimens is associated with advanced pathologic stage. Prostate 2005;64:40-49.

18. O'Brien TS, Fox SB, Dickenson AJ, et al. Expression of the angiogenic factor thymidine phosphorylase/platelet-derived endothelial cell growth factor in primary bladder cancers. Cancer Res 1996;56: 4799-4804.

19. Miyake H, Hoshimura K, Hara l, et al. Basic fibroblast growth factor regulates matrix metalloproteinases production and in vitro invasiveness in human bladder cancer cell lines. J Urol 1997;157: 2351-2355.

20. Sakai Y, Goodison S, Kusmartsev S, et al. Bcl-2 mediated modulation of vascularization in prostate cancer xenografts. Prostate 2009;69: 459-470.

21. Sakai Y, Goodison S, Cao W, et al. VEGF induces expression of Bcl-2 and multiple signaling factors in microvascular endothelial cells in a prostate cancer model. World J Urol 2009;27:659-666.

22. Raghuwanshi SK, Su Y, Singh V, et al. The chemokine receptors CXCR1 and CXCR2 couple to distinct g protein-coupled receptor kinases to mediate and regulate leukocyte functions. J Immunol 2012;189: 2824-2832.

23. Su Y, Raghuwanshi SK, Yu Y, et al. Altered CXCR2 signaling in betaarrestin-2-deficient mouse models. J Immunol 2005;175:5396-5402.

24. Anai S, Sakamoto $\mathrm{N}$, Sakai $\mathrm{Y}$, et al. Dual targeting of $\mathrm{Bcl}-2$ and VEGF: potential strategy to improve therapy for prostate cancer. Urol Oncol 2011;29:421-429.

25. Park MJ, Kwak HJ, Lee HC, et al. Nerve growth factor induces endothelial cell invasion and cord formation by promoting matrix metalloproteinase-2 expression through the phosphatidylinositol 3-kinase/Akt signaling pathway and AP-2 transcription factor. J Biol Chem 2007;282:30485-30496.

26. Maeshima Y, Colorado PC, Torre A, et al. Distinct antitumor properties of a type IV collagen domain derived from basement membrane. J Biol Chem 2000;275:21340-21348.

27. Bonfil RD, Vinyals A, Bustuoabad OD, et al. Stimulation of angiogenesis as an explanation of Matrigel-enhanced tumorigenicity. Int J Cancer 1994:58:233-239.

28. Prewett $M$, Huber J, Li Y, et al. Antivascular endothelial growth factor receptor (fetal liver kinase 1) monoclonal antibody inhibits tumor angiogenesis and growth of several mouse and human tumors. Cancer Res 1999:59:5209-5218.

29. Pang X, Yi Z, Zhang X, et al. Acetyl-11-keto-beta-boswellic acid inhibits prostate tumor growth by suppressing vascular endothelial growth factor receptor 2-mediated angiogenesis. Cancer Res 2009;69: 5893-5900.

30. De-Chao Yu Jun g-Sun Lee, Yoo JiYoung, Shin Hyewon, et al. Soluble vascular endothelial growth factor decoy receptor FP3 exerts potent antiangiogenic effects. Mol Ther 2012;20:938-947.

31. Fuhler GM, Knol GJ, Drayer AL, et al. Impaired interleukin-8- and GROalpha-induced phosphorylation of extracellular signal-regulated kinase result in decreased migration of neutrophils from patients with myelodysplasia. J Leukoc Biol 2005;77:257-266.

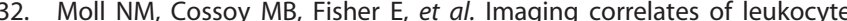
accumulation and CXCR4/CXCL12 in multiple sclerosis. Arch Neurol 2009;66:44-53.

33. Gillitzer R, Goebeler M. Chemokines in cutaneous wound healing. J Leukoc Biol 2001;69:513-521.

34. Hembruff SL, Cheng N. Chemokine signaling in cancer: Implications on the tumor microenvironment and therapeutic targeting. CancerTher 2009;7:254-267.

35. Zhong L, Roybal J, Chaerkady R, et al. Identification of secreted proteins that mediate cell-cell interactions in an in vitro model of the lung cancer microenvironment. Cancer Res 2008;68:7237-7245.

36. Wang $\mathrm{D}$, Wang $\mathrm{H}$, Brown J, et al. CXCL1 induced by prostaglandin E2 promotes angiogenesis in colorectal cancer. J Exp Med 2006;203: 941-951.

37. Baird AM, Gray SG, O'Byrne KJ. Epigenetics underpinning the regulation of the CXC $(E L R+)$ chemokines in non-small cell lung cancer. PLoS One 2011;6:e14593.

38. Warner KA, Miyazawa M, Cordeiro MM, et al. Endothelial cells enhance tumor cell invasion through a crosstalk mediated by CXC chemokine signaling. Neoplasia 2008;10:131-139.

39. Wang D, Richmond A. Nuclear factor-kappa B activation by the CXC chemokine melanoma growth-stimulatory activity/growth-regulated protein involves the MEKK1/p38 mitogen-activated protein kinase pathway. J Biol Chem 2001;276:3650-3659.

40. Wang B, Hendricks DT, Wamunyokoli F, et al. A growth-related oncogene/CXC chemokine receptor 2 autocrine loop contributesto cellular proliferation in esophageal cancer. Cancer Res 2006;66: 3071-3077.

41. Matsushima K, Morishita K, Yoshimura T, et al. Molecular cloning of a human monocyte-derived neutrophil chemotactic factor (MDNCF) and the induction of MDNCF mRNA by interleukin-1 and tumor necrosis factor. J Exp Med 1988;167:883-18793.

42. Matsushima K, Baldwin ET, Mukaida N. Interleukin-8 and MDAF: nove leukocyte recruitment and activity cytokines. Chem Immunol 1992;51:236-265.

43. Koch AE, Polverini PS, Kunkel SL, et al. Interleukin-8 as a macrophagederived mediator of angiogenesis. Science 1992;258:1798-1801.

44. Strieter RM, Kunkel SL, Elner VM, et al. Interleukin-8: a cornea factor that induces neovascularization. Am J Pathol 1992;141: 1270-1284.

45. Wang JM, Taraboletti G, Matsushima K, et al. Induction of hepatotactic migration of melanoma cells by neutrophil activating protein/IL-8. Biochem Biophys Res Commun 1990;169:165-170.

46. Schandendorf D, Moller A, Algermissen B, et al. IL-8 produced by human malignant melanoma cells in vitro is an essential autocrine growth factor. J Immunol 1993;151:2667-2675.

47. Krueger G, Jorgensen C, Miller C, et al. Effect of IL-8 on epidermal proliferation. J Invest Dermatol 1990;94:545.

48. Kaneko T, Zhang Z, Mantellini MG, et al. Bcl-2 orchestrates a cross-talk between endothelial and tumor cells that promotes tumor growth. Cancer Res 2007;67:9685-9693. 